\title{
Study on the Influence of Road Network on the Spatial Distribution of Tourism Resources - A Case Study of the Sichuan-Tibet Scenic Byway
}

\author{
Bo Zhang ${ }^{1,2}$, Boming Tang ${ }^{1}$, Liangyu Zhou ${ }^{3}$, Ke Huang ${ }^{4}$ \\ ${ }^{1}$ School of Civil Engineering, Chongqing Jiaotong University, Chongqing, China \\ ${ }^{2}$ School of Art Design, Chongqing Jiaotong University, Chongqing, China \\ ${ }^{3}$ School of Traffic \& Transportation, Chongqing Jiaotong University, Chongqing, China \\ ${ }^{4}$ College of Architecture and Urban Planning, Chongqing Jiaotong University, Chongqing, China
}

\begin{abstract}
Objectives: The Sichuan-Tibet Scenic Byway is one of the most well-known scenic byway in China. Researching on the mechanism of action between the routes and tourism resources nodes of the Sichuan-Tibet Scenic Byway network, will benefit the Sichuan-Tibet Scenic Byway's development by changing the development patterns of the Scenic Byway from "point-line" to network, and will be helpful to promote the integration of tourism resources along the route, furthermore to construct the Sichuan-Tibet Scenic Byway as a destination of all-for-one tourism. Methods: Based on the spatial design network analysis (sDNA model), GIS spatial analysis and other methods, the current study analyzed regional tourism resources and the spatial characteristics of road network morphology along the Sichuan-Tibet Scenic Byway, and explored the influence of road network forms on the spatial distribution of tourism resources and its spatial spillover effect by combining with spatial econometric model. Results: The distribution pattern of tourism resources along the Sichuan-Tibet Scenic Road is "dense at both ends and sparse in the middle", and the "Matthew Effect" is significant. The spatial structure of road network varies significantly at different scales; at the global scale, the spatial structure shows "one axis and two cores", at the local scale, it shows "two cores and multiple nodes"; Every road network variable has spatial spillover effect on the distribution of tourism resources. The global scale Closeness (NQPDE) has significant positive direct effect and negative spillover effect on tourism resources distribution. Every $1 \%$ increase in local closeness will promote an increase of $0.811 \%$ and $-0.99 \%$ in the distribution of local and adjacent tourism resources, respectively. Betwenness (TPBTE) has significant positive direct effect and positive spillover effect on the distribution of tourism resources. Every $1 \%$ increase in local betwenness will promote an increase of $0.337 \%$ and $1.860 \%$ in the distribution of local and adjacent tourism resources, respectively. Conclusions: The distribution of tourism resources along the Sichuan-Tibet Scenic Byway's shows significant "Matthew Effect". The spatial structure of the Sichuan-Tibet Scenic Byway network varies significantly at different scales. At the global scale, firstly, it has better accessibility and centrality, which is more attractive to the global road network; secondly, the road network is more traversable, which means it bears greater traffic volume, which is more inconsistent with the actual High-grade highways bear more long-distance traffic flows to match; thirdly, they distribution of tourism resources are generally in line with the spatial orientation of National Highway 318. Traffic conditions are an indispensable and important condition for promoting the healthy development of the distribution of regional tourism resources. Closeness (NQPDE) is an important factor affecting the spatial distribution and growth potential of local tourism resources, but it will relatively weaken the development opportunities and cost advantages of tourism resources in neighboring regions, and inhibit the distribution of tourism resources in neighboring regions. Betwenness (TPBtE) is the key to promote global tourism, especially the rapid transportation system can accelerate the integration and reconstruction of tourism elements. This study aims to promote the sound development of the Sichuan-Tibet Scenic Byway network layout and the distribution of regional tourism resources in the post-epidemic era, and to provide reference for the spatial planning of tourism transportation and the optimal allocation of tourism elements.
\end{abstract}

Keywords: Transportation tourism, road network form, spatial distribution, spatial econometric model

ISSN: 0010-8189

www.converter-magazine.info 


\section{Background}

Since the COVID-19 outbreak, the transportation and tourism industries have been greatly impacted. In China, with the effective control of the epidemic, tourism has gradually recovered. The epidemic had great changed Chinese tourists' behavior, especially in the following aspects: First, tourists prefer to travel to places less affected by the epidemic, and overseas travel is still stagnation; second, the willingness of tourists to travel with tour groups has decreased significantly, while autonomous travel has become more popular, and self-driving travel has rapid growth. In the post-COVID-19 era, China's domestic self-drive tourism has obviously recovered. In terms of destination selection, western Sichuan and Tibet located in western China have attracted much attention due to their beautiful scenery, colourful cultural atmosphere and less impact of COVID-19. The Sichuan-Tibet Scenic Byway, one of the most famous and beautiful scenic byways in China, self-driving trips has explosive growth since 2021. Taking Nyingchi city which is an important node along Sichuan-Tibet Scenic Byway as an example, the number of visitors in 2020 has decreased 69.69 in 2020 due to the impact of COVID-19. But the number of visitors to the 2021 peach blossom festival in Nyingchi increased by 32.59 percent compared with the same period in 2019.As a route-type tourist destination, the Sichuan-Tibet Scenic Byway, the type and distribution of nodes in the scenic byway network affect the direction of the scenic byway line, and the layout of the Scenic Byway. ${ }^{1}$ The layout of the Scenic Byway not only affects tourists' travel motivation and destination choice, but also drives the cluster development of destination tourism resources. There are a lot of tourism resources along the Sichuan-Tibet Scenic Byway, but the transportation infrastructure is weak, and regional development imbalance. Explore the coupling mechanism of the route and nodes of the Scenic Byway network, and analyze the characteristics of the Scenic Byway network variables and the spatial differentiation of tourism resources, which can provide guidance for the optimization of the spatial allocation of destination tourism resources and the development of tourism models. At the same time, it is of great significance to enrich and improve the research content and methods of the regional differentiation law of tourism transportation.

\section{Introduction}

The current scholars' research on the impact of traffic on tourism mainly involves the following aspects: First, the impact of traffic on the spatial structure of tourist destinations. Pellegrini A think land transportation is an important factor that affects tourism demand and the length of stay of tourists. ${ }^{2}$ Huang $\mathrm{T}$ et al. ${ }^{3}$ pointed out the impact of rapid transportation on the tourism system of urban agglomerations has increased, strengthening the core-periphery structure of the tourism system of urban agglomerations, and the impact on peripheral cities is more obvious. Li Y.M et al. ${ }^{4}$ indicated the development of transportation has made the effect of "space-time compression" in the region significant, promoting the evolution of the spatial structure of the regional tourism system from the "stripe" model to the "point-axis-plane" and then to the "plate" form. Second, the coupling mechanism of traffic and tourism. Ye $\mathrm{M}$ et al. ${ }^{5}$ according to the synergetics perspective, it combs the coupling mechanism of tourism development and transportation, and empirically analyzes the characteristics and effects of the coupling and coordinated temporal and spatial evolution of transportation and tourism systems. Wang $\mathrm{F}^{6}$ put forward a dynamic mutual-feeding coupling relationship between the transportation network and the evolution of tourism spatial structure. Third, the impact of traffic on the development of regional tourism. Zhang $\mathrm{H} \mathrm{Y}$ et al. ${ }^{7}$ pointed out the development of transportation has led to the initial agglomeration of tourism industries, compressing space-time distances and perception distances, significantly increasing monetary externalities, technical externalities, and spatial costs, and further improving the level of regional tourism industry agglomeration.

Spatial Design Network Analysis quantifies the spatial division of the Scenic Byway network, analyzing the laws of traffic travel, spatial function and spatial form in the regional transportation network system. The use of spatial organization modeling methods can better reveal the interaction between spatial topological forms and spatial social and cultural functions. In recent years, some scholars have begun to use spatial syntax or spatial design network analysis to analyze the influence of road network morphology on spatial distribution. Zhao et al. ${ }^{8}$ use road

ISSN: 0010-8189 
network variable indicators such as intermediate degree, centrality, coverage, and roundaboutness can measure the impact of road network on population distribution and community spatial distribution. Cooper et al. ${ }^{9}$ analyzed the impact of changes in urban spatial layout on pedestrian flow based on the multivariate mixed space design network model (MH-sDNA). An empirical study by Huang Mengzhen et al. ${ }^{10}$ on parks in Nansha District of Guangzhou showed that the distribution of urban parks is greatly affected by the shape of the road network, and pointed out that the impact of the global road network is greater than the impact of the local road network. The empirical research of Xu Zetan et al. ${ }^{11}$ found that there is a significant correlation between the urban road network form of Fuzhou and the retail layout, and the global concentration (Closeness) has the highest correlation with the overall retail layout.

New economic geography shows that the heterogeneity and proximity of geographic space influence and determine the industrial cooperation and development spillover between different regions, and the existence of spillover effects will promote regional coordinated growth. ${ }^{12,13}$ Due to the natural spatial coupling between transportation development and tourism development, each road network variable has significant spatial heterogeneity, and its spillover and diffusion have an important impact on the development of the tourism industry. Scholars have conducted research on the spatial spillover effects of transportation on regional tourism development, tourism economy, and tourism flow spatial structure along the route. Guo X Y et al. ${ }^{14,15}$ in the Yangtze River Economic Zone and Yunnan have shown that the development of highway traffic has a significant spatial spillover effect on the urban tourism economy, and high-value tourism economic areas have significant dependence on areas with high-developed highway traffic. Wang $\mathrm{Z} \mathrm{Y}^{16}$ pointed out that rapid traffic has a significant positive direct effect on tourism flows in the region, and a significant positive spatial spillover effect on tourism flows in surrounding areas, and the spatial spillover effect generated is greater than the direct effect.

In summary, previous studies have explored the impact of road network variables on spatial distribution and the impact of traffic on tourism development. However, there are still the following shortcomings. The influence of traffic on the spatial distribution of tourism resources. (1) The existing literature mainly focuses on the influence mechanism of the accessibility variable of the road network variables on the spatial distribution of tourism resources, and there is little research on the other road network morphological variables. (2) There are few studies on the impact of traffic spillover effects on the spatial distribution of tourism resources, and the research on the spatial correlation and interaction between road network variables and the spatial distribution and agglomeration effects of regional tourism resources needs to be deepened. We takes the area along the Sichuan-Tibet Scenic Byway as the research area, and uses spatial design network analysis and GIS spatial analysis to calculate the spatial distribution characteristics of road network variables and tourism resources. Empirically test the influence of road network form on the spatial distribution of tourism resources and its spatial spillover effects using spatial measurement methods. Exploring the spatial effects of traffic on the spatial distribution of tourism resources from the perspective of road network morphology, in order to provide a reference for regional tourism transportation planning and the optimal allocation of tourism elements.

\section{Methods}

\subsection{Nearest neighbor index and the standard deviational ellipse}

The nearest neighbor distance method is to calculate the average distance between the tourist resource point along the Sichuan-Tibet Scenic Byway and its nearest neighbor tourist resource point, aiming to measure and compare the dispersion degree of different tourist resource elements in the study area. If the average distance is less than the average distance in the hypothetical random distribution, the analyzed feature is considered as a cluster feature, otherwise the feature is considered as a scattered feature.

The standard deviation has five basic elements: X, Y center, long, short, and azimuth. The center represents the relative position of the spatial distribution of geographical elements, the azimuth angle represents the main trend direction of development, the semi-major axis represents the core edge structure of the degree of dispersion of ISSN: 0010-8189 
geographic elements in the main trend direction, and the semi-minor axis represents the degree of dispersion of geographic elements in the secondary direction.

\subsection{Measured weighted kernel density}

Kernel density analysis is an important method to explore the gathering area of regional structure. It can continuously simulate the distribution density of spatial point elements or line elements, effectively mining the gathering area of elements. We takes into account the different influences of different metric values and scales, different metric values and scales are weighted in the calculation. The kernel density is generally defined as: supposing $x, \ldots, x_{i}$ is an independent and uniformly distributed sample drawn from the population whose distribution density function is $\mathrm{f}$, Estimating $\mathrm{f}$ is the value at the point $\mathrm{x}$, Commonly used are Rosenblatt-Parzen kernel estimation ${ }^{17}$ :

$$
f_{n}(x)=\frac{1}{n h} \sum_{n}^{i=1} k\left(\frac{x-x_{i}}{h}\right)
$$

In the formula: $\mathrm{k}$ is kernel function; $\mathrm{h}$ is bandwidth, $\mathrm{h}>0, \quad x-x_{i}$ is the distance from the estimated point to the line element.

\subsection{Spatial design network analysis}

The sDNA model (Spatial Design Network Analysis) is a complex spatial network analysis technology evolved from the traditional space syntax. It has a good application prospect in today's urban and regional-scale spatial analysis $^{18,19}$. By redefining the nodes and chains in graph theory, sDNA uses the chains in the network as the analysis unit to analyze the reachability and centrality of the road network, and can also calculate the potential for pedestrians, motor vehicles and public transportation. In terms of modeling, the road center line is used to construct the traffic network, and the open map data such as OSM can be directly analyzed. In the search radius, compared with the traditional space syntax based on discrete space pattern, sDNA model provides discrete and continuous space pattern, and the calculation of continuous space is relatively accurate. Therefore, we selects continuous space pattern; In terms of measurement indicators, this paper selects Closeness, Betwenness, Severance and Efficiency to measure the regional road network of the Sichuan-Tibet Scenic Byway. The description and calculation methods are as follows

\subsubsection{Closeness}

The closeness represents the difficulty of a road network to the rest of the search radius road networks with high closeness usually have high accessibility and centrality and are more attractive to regional traffic flow.

$$
N Q P D(\mathrm{x})=\sum_{y \in R_{X}} \frac{(W(y) P(y))^{n q p d n}}{d_{M}(x, y)^{n q p d d}}
$$

In the formula: $W(y)$ is the weight of chain $y ; P(y)$ is the weight of node $\mathrm{y}$ in Radius; we use continuous analysis, so $P(y) \in[0,1] ; d_{M}(x, y)$ is the shortest topological distance from x node to $y$ node; nqpdn, nqpdd often take 1 .

\subsubsection{Betwenness}

Betwenness is usually used to measure the probability of traffic flow within the search radius of the road network. The degree of betwenness is directly propotional to the trafficability of the road network, and accordingly carries more traffic flow.

ISSN: 0010-8189 


$$
\begin{gathered}
O D(y, z, x)= \begin{cases}1, & \text { if } x \text { is on the first geodesic found from } y \text { to } z \\
1 / 2, & x=y \neq \mathrm{z} \\
1 / 2, & x=z \neq y \\
1 / 3, & x=y=z \\
0, & \text { otherwise }\end{cases} \\
\operatorname{TPBt}(x)=\sum_{y \in N N_{z} \in R_{y}} O D(y, z, x) \frac{W(x) P(x)}{\text { totalweight }(y)}
\end{gathered}
$$

In the formula: $O D(y, z, x)$ is the shortest topological path between $\mathrm{y}$ and $\mathrm{z}$ in the search radius through node $\mathrm{x}$; totalweight $(y)$ is the total weight of $y$ within the radius.

\subsubsection{Severance}

Severance reflects the oppositeness of closeness in network detour analysis. This paper measure the difficulties of travel space shange by measuring the distortion of highway traffic network. The severance is reflected by calculating the Mean Crow Flight $(M C F)$ and the Diversion Ratio (DIV).Mean Crow Flight $(M C F)$ is the mean of the crow flight distance between each origin and all links within the radius. Diversion Ratio (Div) is the mean ratio of geodesic length to crow flight distance over all links in the radius, quantifying the distance the shortest network distance deviates from crow flight.

$$
\operatorname{Div}(x)=\frac{\sum_{y \in R_{x}} \frac{d_{M}(x, y)}{C F D(x, y)} W(y) P(y)}{\sum_{y \in R_{x}} W(y) P(y)}
$$

where $\operatorname{CFD}(\mathrm{x}, \mathrm{y})$ is the crow flight distance between the centers of $\mathrm{x}$ and $\mathrm{y}$.

\subsubsection{Efficiency}

The above methods focus on spatial network analysis, and efficiency is used to measure the accessibility of the chain covering the regional space or distance covered by the spatial network. The above methods focus on spatial network analysis, and efficiency is used to measure the accessibility of the chain covering the regional space or distance covered by the spatial network. The convex hull principle is to measure the efficiency of spatial network by calculating HullR and HullSI within each network radius. The maximum convex hull radius $(H u l l R)$ is the distance from the origin to the point of the maximum convex hull radius, and is the maximum average straight-line distance to any point within the network radius. straight-line distance to any point within the network radius.

$$
H u l l R=\max \left\{M C F(x)=\frac{\sum_{y \in R_{x}} C F D(x, y) W(y) P(y)}{\sum_{y \in R_{x}} W(y) P(y)}\right\}
$$

(5) Radius (R)

The search radius is calculated by calculating the space range of a certain section in the road network under the specified measurement. When the search radius is $\mathrm{N}$, that is, the characteristics of all other road sections are taken into account in the calculation of road network variables. The empirical research on spatial network of several urban agglomerations shows that the spatial network structures analyzed at different scales are different. ${ }^{20}$ Therefore, we choose $\mathrm{N}$ as the calculation radius at the macro scale, aiming to analyze the spatial network structure

ISSN: 0010-8189 
at the global scale. Taking $100 \mathrm{~km}$ and $200 \mathrm{~km}$ as meso-scale analysis radii and $50 \mathrm{~km}$ as micro-scale analysis radii, this paper aims to reflect the spatial fabric from landscape to road network at local scale and explain the differences of geometric correlation mechanisms at different scales.

\subsection{Bivariate moran index}

The bivariate global Moran index is to explore the coupling relationship between tourism resource density and sDNA measurement density at different scales. The global Moran's I can measure the relationship between spatial elements, and its value is between $[-1,1]$. When it is greater than 0 , it means that there is a positive spatial correlation, and the closer it is to 1, the higher the degree of agglomeration of spatial elements; when it is equal to 0 , it means that there is no spatial autocorrelation, present random distribution. The global Moran's I index is calculated as follows:

$$
I=\frac{n \sum_{n}^{i=1} \sum_{n}^{j=1} w_{i j} z_{x i} z_{y j}}{\sum_{n}^{i=1} \sum_{n}^{j=1} w_{i j} \sum_{n}^{i=1} z_{x i} z_{y j}}
$$

In the formula, $\mathrm{I}$ is the bivariate Moran index, $\mathrm{n}$ is the number of counties, ${ }^{z_{x i}}$ and ${ }^{z_{y j}}$ represent the standardized values of nuclear density values of tourism resources and sDNA metric values, $W$ is the spatial weight matrix of geographic distance.

\subsection{Spatial durbin model}

The spatial durbin model and spatial durbin error model can not only measure the influence of road network variables on the spatial distribution of tourism resources, but also measure the influence of road network variables on the spatial distribution of tourism resources in surrounding areas by the product of weight matrix and explanatory variables. The spatial dependence of the spatial Durbin error model exists in the disturbance term error, which describes the influence degree of the error shock of the explained variable in the adjacent area on the explanatory variable ${ }^{21,22}$. Therefore, we established a spatial Durbin error model system with internal correlation and external impact stimulation, and studied the influence of road network variables on the spatial distribution of tourism resources by using Closeness, Betwenness, Severance and Efficiency calculated by SDNA model.

When selecting the spatial weight matrix, according to the comparative study of different methods for selecting the spatial weight matrix by Wang $\mathrm{H} \mathrm{L}$ et al. ${ }^{23}$ the reciprocal of the shortest distance between each county is selected as the weight. In this way, the geographical distance factor that has the greatest influence on traffic can be fully considered. At the same time, the possible interaction between two cities with close but not adjacent geographical distances can be investigated. The spatial weight matrix of geographical distance is expressed as follows:

$$
W=\left\{\begin{array}{cc}
\frac{1}{d^{2} i j} & i \neq j \\
0 & i=j
\end{array}\right.
$$

In the formula, $\mathrm{i}$ and $\mathrm{j}$ represent $\mathrm{i}$ (area, city) and $\mathrm{j}$ (area, city) respectively, $\mathrm{d}$ represents the linear distance between (area, city), and $\mathrm{d} 2$ represents the square of the linear distance. Since the spatial weight matrix of geographical distance is set according to the reciprocal of geographical distance, the closer the distance between (districts and cities), the greater the weight.

The spatial Durbin Model (SDM) is expressed as:

$$
Y=\rho W Y+X \beta+W X \theta+\varepsilon
$$

The spatial Durbin error model (SDEM) is expressed as follows:

ISSN: 0010-8189

(C) CONVERTER 2021

www.converter-magazine.info 


$$
\begin{gathered}
Y=X \beta+W X \theta+\mu \\
\mu=\lambda W \mu+\varepsilon
\end{gathered}
$$

In the formula, $Y$ is the explained variable; $X$ is the explanatory variable matrix; $W$ represents the spatial weight matrix ( $\mathrm{N}^{*} \mathrm{~N}, \mathrm{~N}$ is the number of county units); $\theta, \lambda$ and $\beta$ are the parameter vectors of explanatory variables. $\mu$ is a random error vector with normal distribution. $\varepsilon$ is a random error term vector, and the spatial dependence in the disturbance term error describes the influence degree of the explanatory variables in the adjacent region on the error impact of the factor vector. In the model constructed in this paper, the explanatory variable $Y$ is the tourism resource distribution index TrKernel, and the explanatory variable $\mathrm{X}$ includes Closeness: NQPDE, Betwenness: TPBtE, Severance: DivE and Efficiency: HullR.

\section{Spatial distribution of tourism resources and road network structure analysis in Sichuan-Tibet Scenic Byway}

\subsection{Research area and data source}

Based on the "National Ecotourism Development Plan ( 2016-2025)" Sichuan-Tibet Scenic Byway ( Chengdu, Ya 'an, Kangding, Batang, Nyingchi, Lhasa ), this paper selected Wuhou District, Chengdu City, Sichuan Province as the start potin, including along the Shuangliu district, Xinjin, Pujiang, Qionglai, Yucheng District, Mingshan District, LuShan, Tianquan, Luding county, Kangding, Yajiang, Litang county, Batang county, Mangkang county, ZuoGong county, Bomê County, Nyingchi, Gongbujiangda County, Maizhokunggar County, the Dagzê District. west to the Chengguan district of Lhasa, the capital of Tibet. As a ' world-class landscape corridor ', Sichuan-Tibet Scenic Byway is one of the most popular self-driving routes in China. It has entered the public self-driving tour consumption vision from the western national defense strategic highway. The natural landscape along the line is rich and diverse, and the natural and cultural tourism resources endowment value is high.

The tourism resource point data in the study area comes from Gaode maps. By using the web crawler tool to crawl geographic location information and being combined with the Sichuan Provincial Department of Culture and Tourism and the Tibet Autonomous Region Tourism Development Department's public A-level scenic spot list to screen the acquired data, we obtain a total of 94 effective tourism resource points. The Scenic Byway data comes from Open-Street map. The topological relationship is checked and edited. Combined with manual interpretation, the fusion and cleaning are carried out, and the required road network is generated after clearing the null value, interoperability, disconnection and repetition. The sDNA toolbox was loaded on ArcGIS platform and the road axis of the study area was extracted. The measurement values of each road under the search radius of $50 \mathrm{~km}, 100$ $\mathrm{km}, 200 \mathrm{~km}$ and $\mathrm{N}$ were calculated. The weighted kernel density of the measured values at different scales was calculated by kernel density method to detect the spatial characteristics of the landscape road network structure.

\subsection{Spatial distribution characteristics of Sichuan-Tibet Scenic Byway tourism resources}

\subsubsection{Spatial structure analysis}

Due to the significant differences in the resource level and tourism economic development level in the areas along the Sichuan-Tibet Highway Scenic Byway, there are also significant differences in the spatial distribution of different star tourism resources. In order to grasp the spatial distribution of star-level tourism resources, the nearest neighbor index is used to determine whether the regional spatial distribution along the Sichuan-Tibet Scenic Byway is random, uniform or agglomeration. The average nearest distance is calculated by spatial statistical tools, and the nearest index and distribution type of regional tourism areas along the Sichuan-Tibet Scenic Byway are obtained. The Table 1 show that the nearest neighbor index of $5 \mathrm{~A}$ tourist area is $1.792>1$, and the spatial distribution type is uniform distribution. The nearest neighbor indexes of 4A, 3A, 2A and below are $0.745,0.642$ and 0.818 , respectively, which are less than 1 . The distribution type is condensed distribution. The nearest

ISSN: 0010-8189 
neighbor index of all tourism resources is $0.562<1$, and the distribution type is condensed.

Table 1 Spatial structure analysis

\begin{tabular}{|l|c|c|c|c|}
\hline \multicolumn{1}{|c|}{ Class } & $\begin{array}{c}\text { mean observation } \\
\text { distance/ }(\mathrm{m})\end{array}$ & $\begin{array}{c}\text { expected observation } \\
\text { distance } /(\mathrm{m})\end{array}$ & $\begin{array}{c}\text { nearest } \\
\text { neighbor } \\
\text { ratio }\end{array}$ & Condensed type \\
\hline 2A and below & 36810.890 & 44972.220 & 0.818 & cluster \\
\hline $3 \mathrm{~A}$ & 19741.153 & 30746.420 & 0.642 & cluster \\
\hline 4A & 27195.577 & 36505.392 & 0.745 & cluster \\
\hline 5A & 94638.357 & 52806.943 & 1.792 & dispersion \\
\hline All & 13391.828 & 23797.316 & 0.562 & cluster \\
\hline
\end{tabular}

4.2.2 Spatial distribution direction analysis

In order to detect the directional distribution characteristics of star-level tourism resources in the area along the Sichuan-Tibet Highway Scenic Byway, the parameters corresponding to the spatial distribution trend are obtained. On the whole, the regional tourism resources along the Sichuan-Tibet Scenic Byway show the spatial distribution pattern of 'northeast-southwest'. At the same time, it can be found in Table 2 that the long axis is 'northeast-southwest', and the short axis is 'northeast-southwest', indicating that the main distribution trend of tourism resources is 'northeast-southwest', and the distribution is more intensive in the 'northeast-southwest'. From the perspective of tourism resources at all levels, the tourism resources of 4A, 3A and $2 \mathrm{~A}$ and below show the spatial distribution pattern of northeast-southwest, which is consistent with the overall spatial distribution level of tourism resources. Compared with the overall tourism resources, the elliptical area of 5A, 4A, 3A, 2A and below tourism resources is 0.65 times, 0.88 times, 0.75 times and 0.93 times of the overall tourism resources, indicating that the overall distribution trend of tourism resources is more discrete. It shows that the distribution of tourism resources is mainly in Chengdu and Ya'an counties in the northeast direction of the study area and Lhasa and Nyingchi counties in the southwest direction. Chengdu and Ya'an counties have obvious geographical location advantages, high degree of openness, strong economic strength, and increasing tourism investment, so the tourism industry can be steadily developed.

Table 2 Spatial distribution direction analysis

\begin{tabular}{|l|c|c|c|c|}
\hline \multicolumn{1}{|c|}{ class } & long axis/(m) & short axis/(m) & $\begin{array}{c}\text { Rotation } \\
\text { Angle/ }\left({ }^{\circ}\right)\end{array}$ & Area/km ${ }^{2}$ \\
\hline 2A and below & 608299.017 & 42903.116 & 88.425 & 81676.868 \\
\hline 3A & 517612.096 & 40747.646 & 87.277 & 66057.803 \\
\hline 4A & 588144.107 & 42245.537 & 85.758 & 77770.790 \\
\hline 5A & 718040.945 & 25449.359 & 90.049 & 56566.232 \\
\hline All & 641823.489 & 43622.849 & 87.406 & 87598.528 \\
\hline
\end{tabular}

4.2.3 Kernel density analysis

The kernel density analysis tool in ArcGIS 10.2 software was used to analyze the kernel density of tourist areas. The search radius was $18 \mathrm{~km}$. The results are shown in Figure 1. It can be seen from the figure that the distribution of regional tourism resources along the scenic road of Sichuan-Tibet Highway is relatively compact along National Highway 318 and Chengdu and Lhasa, which is significantly different from the distribution of Tibet-related areas in Sichuan and Changdu, overall showing a ' dense two ends, sparse middle ' distribution pattern, with significant 'Matthew Effect' ${ }^{\text {'2 }}$. The high-value areas show a hierarchical group structure with Chengdu, Ya'an and Lhasa as the core, and the distribution of tourism resources in the adjacent areas shows a gradient decreasing trend, while the low-value areas of tourism resources show a scattered shape and the location points to the provincial fringes of Sichuan and Tibet, forming a hierarchical ' center-periphery' spatial structure.

ISSN: 0010-8189

(C) CONVERTER 2021

Www.converter-magazine.info 


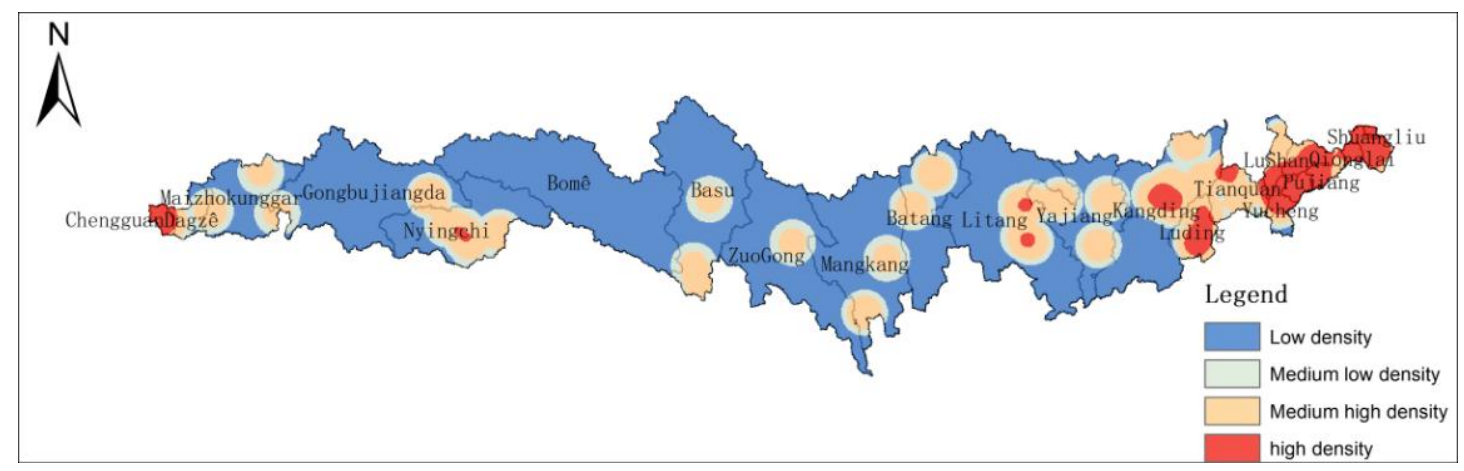

Fig 1: Kernel density analysis of tourism resources on Sichuan-Tibet Scenic Byway

4.3 Analysis of Sichuan-Tibet highway landscape road network morphology

4.3.1 'Axis-two-core' road network structure at global scale

By analyzing the global closeness and global betwenness of the areas along the Sichuan-Tibet Scenic Byway, the overall landscape road network structure of "one axis, two cores" is presented, with a pattern of massive agglomeration and axial extension. The 'one axis' takes Chengdu and Lhasa as two ends, relying on Ya'an, Kangding, Nyingchi 318 national highway, Ya'an-Kangding highway and other traffic trunk lines along the line to form a basic skeleton of the east-west development axis. 'Two nuclear' is the study area of Chengdu, Lhasa jurisdiction counties as the core. 'Axis and cores ' are the high value areas of global closeness and global betwenness in the study area. The first is that the region has better accessibility and centrality on the global scale, and has stronger attraction to the global road network. The second is that the road network in the region has a high ride-through, that is, it undertakes a larger traffic volume, which matches the actual high-grade highway undertaking more long-distance traffic flow; The third is that it is consistent with the spatial trend of National Highway 318 on the whole.

4.3.2'Two-core multi-node' road network structure at local scale

By analyzing the Cloesness, betwenness, Severance and Efficiency of each local scale, the spatial network structure of ' two cores and multiple nodes ' is presented as a whole. The 'two core' is composed of Chengdu and Lhasa, and the ' multi-node ' is composed of Kangding, Litang, Ya'an and Nyingchi in Ganzi Tibetan Autonomous Prefecture. When the search radius is $50 \mathrm{~km}$, only Chengdu city, Lhasa city and the core city of each town have higher local proximity and penetration, indicating that the accessibility and passing ability of the global road network of short-distance travel are poor, and the attraction of the road network in each city is strong. When the search radius is $100 \mathrm{~km}$ and $200 \mathrm{~km}$, the accessibility and centrality are significantly improved and evenly distributed, indicating that the regional group has close internal connection, centrality and good traffic crossing.

4.3.3 Significant differences in road traffic network structure at different scales

In order to detect the spatial structure differences of highway traffic network at different scales, the sDNA parameters calculated based on the road network elements are aggregated to the county geographic unit ${ }^{25}$ by using the spatial join tool in ArcGIS, and the average closeness, average betwenness, average separation and average efficiency of each county highway are calculated. Among them, the differences of closeness, betwenness and efficiency are the most significant. The five county units with the highest average closeness have evolved from Wuhou District, Chengguan District, Shuangliu District, Xinjin District and Qionglai City at the micro scale to Wuhou District, Chengguan District, Shuangliu District, Xinjin District and Yucheng District at the global scale. It can be seen that the average closeness value of each county unit increases only with the increase of search radius, which reflects that the vitality center in the study area is always the core city of each urban group.The five county units with the highest average betwenness have evolved from Shuangliu District, Wuhou District, Xinjin District, Yucheng District and Qionglai District at the micro scale to Basu County, Batang County, Gongbujiangda County, Dazi District and Mingshan District at the global scale. It can be seen that the search radius has evolved from local

ISSN: 0010-8189

www.converter-magazine.info 
to global, and the county unit with high degree of travel has also evolved from the tourism resource polar core area to the county unit along the main axis of '318 national highway', reflecting that the travel degree of the short-distance travel center is, and the travel degree of the connecting channel between the long-distance travel areas is high. At the same time, it shows that the high value area of the global scale only undertakes the traffic function on the global scale, which attracts the traffic flow of long distance travel and lacks the ability to attract the traffic flow of close distance, and the analysis result are shown in Figure 2.
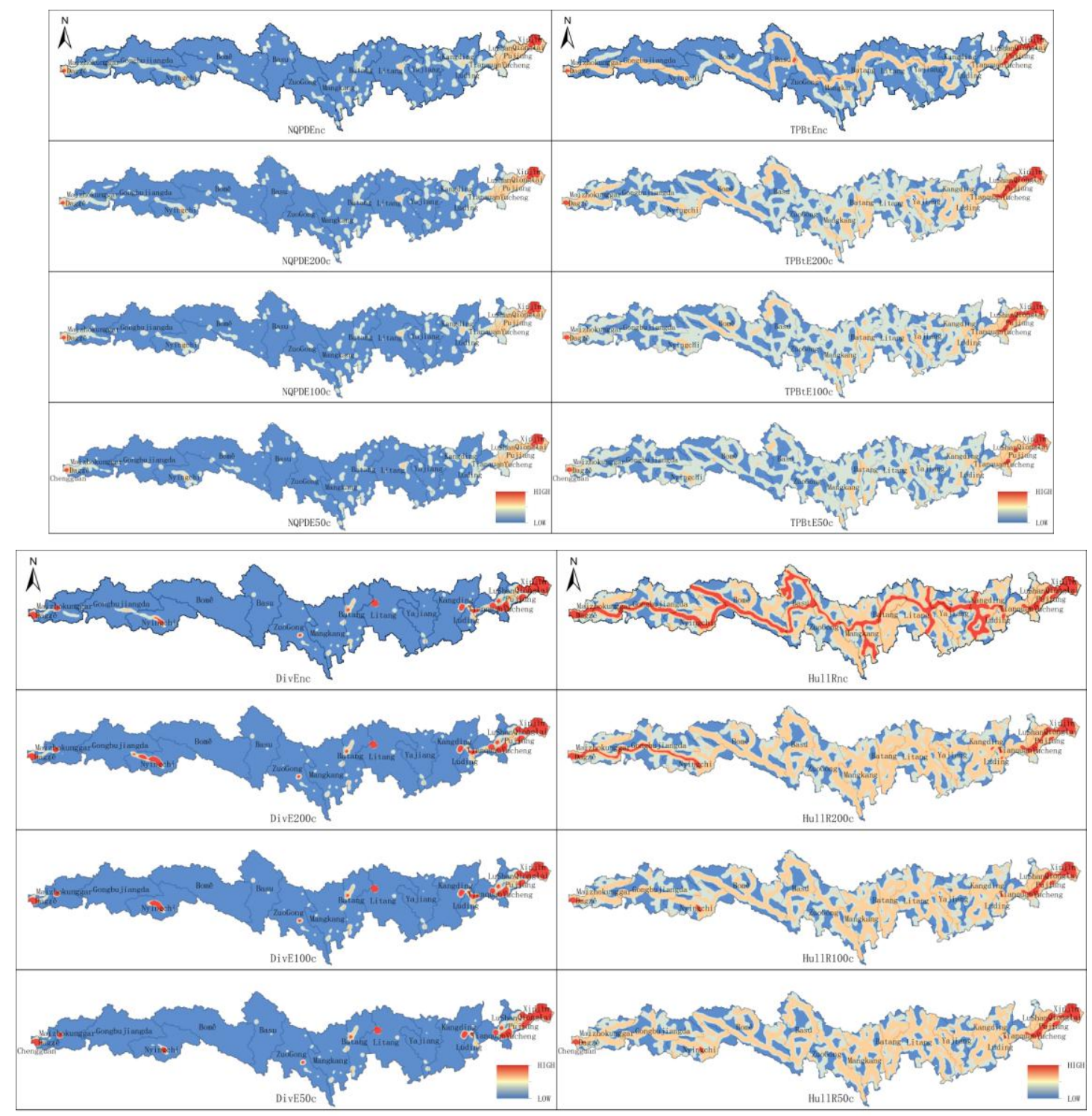

Fig 2: Analysis of weighted kernel density of road network fabric on Sichuan-Tibet Scenic Byway

\section{Analysis of influencing factors of road network form on spatial distribution of tourism resources}

\subsection{Bivariate global autocorrelation analysis}

Before using the spatial econometric model to measure the influence of road network morphology variables on the spatial distribution of tourism resources, the global Moran ' $\mathrm{s}$ I index of bivariate is used to reveal the spatial correlation model between them. This section uses Geoda to calculate the global Moran's I index of the county unit along the Sichuan-Tibet Scenic Byway. It is found that the Euclidean distance threshold of adjacent counties is $120.342 \mathrm{~km}$. The results are shown in Table 3. Except that the severance under the search radius of $100 \mathrm{~km}$ and

ISSN: 0010-8189 
$200 \mathrm{~km}$ does not pass the significant level test, the other road network variables at different scales pass the significant level test. The Moran ' $\mathrm{s}$ I index is 0.247 at $50 \mathrm{~km}$ search radius, and increases to $0.256,0.263$ and 0.263 at $100 \mathrm{~km}, 200 \mathrm{~km}$ and $\mathrm{N}$ search radius, respectively. It shows that there is a positive spatial correlation between road network closeness and spatial distribution of tourism resources at all scales, and at least through $5 \%$ significance test. At the same time, it is found that with the increase of search radius, there is an upward trend. Compared with the local scale, the mutual promotion effect of the two is improved in the global scale. The Moran ' $\mathrm{s} I$ index under the search radius of $50 \mathrm{~km}$ is 0.342 , which increases to 0.583 and 0.559 under the search radius of $100 \mathrm{~km}$ and $200 \mathrm{~km}$ respectively, and decreases to-0.071 under the global search radius, showing an inverted ' V ' shape feature of first increase and then decrease. At least $10 \%$ significance test shows that the overall spatial dependence and correlation characteristics of the two are obvious. Therefore, the spatial effect cannot be ignored when studying the spatial relationship between road network morphology variables and spatial distribution of tourism resources.

Table 3 Bivariate global autocorrelation analysis

\begin{tabular}{|l|l|l|l|l|}
\hline Radius & $50 \mathrm{~km}$ & $100 \mathrm{~km}$ & $200 \mathrm{~km}$ & $\mathrm{~N}$ \\
\hline NQPDE & $0.247^{* *}$ & $0.256^{* *}$ & $0.263^{* *}$ & $0.263^{* *}$ \\
\hline TPBtE & $0.342^{* *}$ & $0.406^{* * *}$ & $0.472^{* * *}$ & $-0.071^{*}$ \\
\hline DivE & $0.106^{*}$ & 0.094 & 0.099 & $0.177^{*}$ \\
\hline HullR & $-0.223^{* *}$ & $-0.180^{* *}$ & $-0.131^{*}$ & $-0.313^{* * *}$ \\
\hline
\end{tabular}

Note: $* * * * * *$ indicated the adoption of $1 \%, 5 \%, 10 \%$ significance test level

\subsection{Empirical Analysis of spatial durbin model}

There is a significant spatial correlation between the road network variables and the spatial distribution of tourism resources along the Sichuan-Tibet Scenic Byway. The existence of spatial spillover effect cannot be ignored when studying the spatial relationship between the two. With STATA 15 software as the computing platform, the Spatial Durbin model is used to obtain the estimation and test results of the impact of traffic service function on tourism efficiency. In order to compare the advantages and disadvantages of the models, the Spatial Durbin Model (SDM) and Spatial Durbin Error Model (SDEM) are used for maximum likelihood estimation. The table is the empirical results estimated by using the method of constructing Spatial Autoregressive Model in STATA15. It can be seen that the natural logarithm likelihood function value (Log Likelihood) of SDEM model is generally higher than that of SDM model, BIC of the SDEM model are generally lower than those of the SDM model. So the author explains and analyzes the results of SDEM model. According to the model parameter estimation results in Table 4, the Closeness (NQPDE) at each scale, the Betwenness (TPBtE) at the meso-scale and global scale passed the significance level test. At the global scale, the elastic coefficient of proximity ranks first among all indexes, which means that the impact of accessibility and centrality on the spatial distribution of tourism resources increases by $0.811 \%$ every $1 \%$ increase in the global scale, indicating that accessibility and centrality have a considerable weight to promote the spatial distribution of tourism resources. This is consistent with the current domestic and international conclusion that the improvement of accessibility brings ' space-time compression ' effect, reduces travel space-time cost, and then improves the development of destination tourism resources (Li.2018). It is proved that road network accessibility is an indispensable prerequisite for regional tourism development.

Table 4 Regression results of SDM model and SDEM model

\begin{tabular}{|l|c|c|c|c|c|c|c|c|}
\hline \multirow{2}{*}{} & \multicolumn{2}{|c|}{$50 \mathrm{KM}$} & \multicolumn{2}{c|}{$100 \mathrm{KM}$} & \multicolumn{2}{c|}{ 200KM } & \multicolumn{2}{c|}{$\mathrm{N}$} \\
\cline { 2 - 9 } & SDM & SDEM & SDM & SDEM & SDM & SDEM & SDM & SDEM \\
\hline$N Q P D E$ & $0.909 * * *$ & $0.899 * * *$ & $0.602 * * *$ & $0.572 * * *$ & $0.565 * * *$ & $0.645 * * *$ & $0.831 * * *$ & $0.811 * * *$ \\
\hline
\end{tabular}

ISSN: 0010-8189

(C) CONVERTER 2021

Www.converter-magazine.info 
CONVERTER MAGAZINE

Volume 2021, No. 5

\begin{tabular}{|l|c|c|c|c|c|c|c|c|}
\hline TPBtE & -0.093 & -0.177 & $0.410^{*}$ & $0.157 *$ & $0.492 * * *$ & $0.369 * * *$ & $0.318^{* *}$ & $0.337 * *$ \\
\hline DivE & -0.126 & -0.133 & $-0.256^{* *}$ & $-0.209 * * *$ & $-0.220 * * *$ & $-0.199 * * *$ & -0.117 & -0.101 \\
\hline HullR & -0.048 & -0.082 & 0.003 & $-0.116^{*}$ & -0.088 & $-0.154 *$ & 0.226 & 0.207 \\
\hline$W^{* N Q P D E}$ & 1.169 & 1.494 & 0.642 & 0.689 & -0.062 & $3.287 * * *$ & $2.419 * *$ & $2.599 * *$ \\
\hline$W^{*} T P B t E$ & -0.976 & -1.065 & 0.240 & 0.310 & $0.973 * * *$ & $-0.899 * *$ & $-1.606 * * *$ & $-1.273 * * *$ \\
\hline$W^{*}$ DivE & -0.036 & -0.200 & $-1.220 * *$ & $-1.763 * * *$ & $-0.768 *$ & $0.555^{*}$ & 0.646 & $0.713 *$ \\
\hline$W^{*}$ HullR & $2.916 * * *$ & $2.905 * * *$ & $4.401 * * *$ & $3.892 * * *$ & $4.108 * * *$ & $-0.708 *$ & $7.460 * * *$ & $7.400 * * *$ \\
\hline Log-L & 17.784 & 18.305 & 20.492 & 24.003 & 27.721 & 28.186 & 20.733 & 20.327 \\
\hline$R^{2}$ & 0.829 & 0.825 & 0.850 & 0.816 & 0.907 & 0.904 & 0.870 & 0.863 \\
\hline$A I C$ & -13.567 & -14.609 & -18.983 & -26.006 & -32.442 & -34.372 & -19.465 & -18.654 \\
\hline BIC & -1.076 & -2.119 & -6.492 & -13.515 & -19.952 & -21.881 & -6.974 & -6.163 \\
\hline
\end{tabular}

The spatial lag term can't directly see the size of the spatial spillover effect. In order to further explore the mechanism and spatial spillover effect between the spatial distribution of tourism resources and the network structure, the author decomposes the spatial effect of the main body, and analyzes its direct effect, indirect effect and total effect. Table 5 is the decomposition result of the direct effect and indirect effect of the Spatial Durbin Model.

The calculation results of road network morphological parameters at the global scale after entering the model are compared. Closeness $(N Q P D E)$ has significant positive direct effect and negative spillover effect on the distribution of tourism resources; each $1 \%$ increase in local proximity will promote the distribution of tourism resources in local and adjacent areas by $0.811 \%$ and- $0.911 \%$, respectively. Closeness is an important factor in promoting the spatial distribution and growth potential of local tourism resources. Influenced by the spatial interaction theory and the distance attenuation law, the improvement of local centrality and regional traffic vitality will relatively weaken the development opportunities and cost advantages of tourism resources in neighboring regions, and inhibit the distribution of tourism resources in neighboring regions. The area with high Closeness is the area with advantageous traffic location. On the one hand, the regional traffic advantages provide support for regional tourism, on the other hand, it has a 'siphon effect' on the adjacent areas with low traffic advantages. Betwenness (TPBtE) has significant positive direct effect and positive spillover effect on the distribution of tourism resources; each $1 \%$ increase in local penetration will promote the distribution of tourism resources in local and adjacent areas by $0.337 \%$ and $1.860 \%$, respectively. It shows that the improvement of Betwenness is the key to promote global tourism, especially the rapid transportation system to accelerate the integration and reconstruction of tourism elements. The improvement of local Betwenness and road service level promotes the evolution of regional connection strength from 'weak relationship' to ' strong relationship'. High-grade highways such as highways and national highways constitute a strong tourism axis, which promotes the transformation of the spatial structure of tourism resources from 'point' to 'plate', and promotes the development of 'global tourism' along Sichuan-Tibet Scenic Byway.

Table 5 Direct effect, indirect effect and total effect of SDM model and SDEM model

\begin{tabular}{|c|c|c|c|c|c|c|c|c|c|}
\hline & \multicolumn{2}{|c|}{$50 \mathrm{KM}$} & \multicolumn{2}{|c|}{$100 \mathrm{KM}$} & \multicolumn{2}{|c|}{$200 \mathrm{KM}$} & \multicolumn{2}{|c|}{$\mathrm{N}$} \\
\hline & & SDM & SDEM & SDM & SDEM & SDM & SDEM & SDM & SDEM \\
\hline \multirow[t]{4}{*}{$\begin{array}{l}\text { Direct } \\
\text { effect }\end{array}$} & $\begin{array}{l}N Q P D \\
E\end{array}$ & $\begin{array}{c}0.904^{* *} \\
*\end{array}$ & $\begin{array}{c}0.899 * * \\
*\end{array}$ & $\begin{array}{c}0.594 * * \\
*\end{array}$ & $0.572 * * *$ & $0.635 * * *$ & $0.645 * * *$ & $\begin{array}{c}0.775 * * \\
*\end{array}$ & $0.811 * * *$ \\
\hline & TPBtE & -0.089 & -0.177 & $0.413^{*}$ & 0.157 & $0.473 * * *$ & $0.369 * * *$ & $0.434 * *$ & $0.337 * *$ \\
\hline & DivE & -0.125 & -0.133 & $-0.214 * *$ & $\begin{array}{c}-0.209^{* *} \\
*\end{array}$ & $\begin{array}{c}-0.184 * * \\
*\end{array}$ & $\begin{array}{c}-0.199 * * \\
*\end{array}$ & -0.090 & -0.101 \\
\hline & HullR & -0.061 & -0.082 & -0.176 & $-0.116 *$ & $-0.423 * *$ & $-0.154 * *$ & 0.569 & 0.207 \\
\hline
\end{tabular}

ISSN: 0010-8189

(C) CONVERTER 2021

www.converter-magazine.info 
CONVERTER MAGAZINE

Volume 2021, No. 5

\begin{tabular}{|c|c|c|c|c|c|c|c|c|c|}
\hline \multirow[t]{4}{*}{$\begin{array}{l}\text { Indirec } \\
\text { t effect }\end{array}$} & $\begin{array}{l}N Q P D \\
E\end{array}$ & 0.762 & 1.069 & 0.095 & 0.493 & $-0.360 * *$ & $-0.507 * *$ & -1.425 & $\begin{array}{c}-0.911 * * \\
*\end{array}$ \\
\hline & TPBtE & -0.663 & -0.762 & -0.030 & 0.222 & 0.098 & $0.397 *$ & 2.924 & $1.860 * *$ \\
\hline & DivE & -0.019 & -0.143 & $-0.497^{*}$ & $\begin{array}{c}-1.262 * * \\
*\end{array}$ & -0.178 & $-0.644 * *$ & 0.681 & $0.510^{*}$ \\
\hline & HullR & $1.995 *$ & $\begin{array}{c}2.079 * * \\
*\end{array}$ & $\begin{array}{c}2.117 * * \\
*\end{array}$ & $2.785 * * *$ & $1.702 * * *$ & $2.352 * * *$ & 8.645 & $5.295 * * *$ \\
\hline \multirow[t]{4}{*}{$\begin{array}{l}\text { Total } \\
\text { effect }\end{array}$} & $\begin{array}{l}N Q P D \\
E\end{array}$ & $1.666 * *$ & $\begin{array}{c}1.968 * * \\
*\end{array}$ & $0.690 * *$ & $1.065 * *$ & $0.275^{* *}$ & $0.138 * * *$ & $-0.650 * *$ & $\begin{array}{c}-0.100 * * \\
*\end{array}$ \\
\hline & TPBtE & -0.753 & -0.939 & 0.383 & 0.379 & $0.571 * * *$ & $0.766^{* * *}$ & 3.359 & $2.196 * * *$ \\
\hline & DivE & -0.145 & -0.276 & $-0.710 * *$ & $\begin{array}{c}-1.471 * * \\
*\end{array}$ & $-0.363 * *$ & $\begin{array}{c}-0.843^{* *} \\
*\end{array}$ & 0.591 & 0.409 \\
\hline & HullR & $1.935 * *$ & $\begin{array}{c}1.997 * * \\
*\end{array}$ & $\begin{array}{c}1.940 * * \\
*\end{array}$ & $2.669 * * *$ & $1.279 * * *$ & $2.198 * * *$ & 9.214 & $5.502 * * *$ \\
\hline
\end{tabular}

\section{CONCLUSIONS}

Taking the area along the Sichuan-Tibet Scenic Byway as the research case, this paper use spatial design network analysis and GIS spatial analysis to calculate the spatial distribution characteristics of road network variables and tourism resources. Combine with bivariate Moran index and spatial Durbin model to empirically test the influence of road network morphology on the spatial distribution of tourism resources and its spatial spillover effect, and explores the spatial effect of traffic on the spatial distribution of tourism resources from the perspective of road network morphology. The following three basic conclusions are obtained through research:

(1) The regional tourism resources along the Sichuan-Tibet Scenic Byway show a distribution pattern of ' dense at both ends and sparse in the middle ', forming a hierarchical ' center-periphery ' spatial structure, and the ' Matthew Effect ' is significant. The spatial structure of the Sichuan-Tibet Scenic Byway network has significant differences at different scales. On the global scale, the spatial network structure of ' one axis and two cores ' is presented. The first is that the region has good accessibility and centrality on the global scale, which is more attractive to the global road network. The second is that the road network has a high ride-through, which means it undertakes larger traffic volume, matches the actual high-grade highway undertaking more long-distance traffic flow; the third is that it is consistent with the spatial trend of National Road 318 on the whole. The spatial network structure of 'two cores and multiple nodes' is presented at the local scale, and the measurement values are significantly different at each local scale. (2) The overall correlation model between road network variables and the spatial distribution of tourism resources shows significant agglomeration and dependence, indicating that the distribution of tourism resources has a significant dependence on road network variables. When considering the impact of various road network variables on the spatial distribution of tourism resources, the spatial effect cannot be ignored. (3) Each network variable has a spatial spillover effect on the distribution of tourism resources. The closeness (NQPDE) has a significant positive direct effect and negative spillover effect on the distribution of tourism resources. The closeness is an important factor affecting the spatial distribution and growth potential of local tourism resources. However, due to the comprehensive influence of spatial interaction theory and distance attenuation law, the improvement of local centrality and regional traffic vitality will relatively weaken the development opportunities and cost advantages of tourism resources in adjacent areas, and inhibit the distribution of tourism resources in adjacent areas. Betwenness (TPBtE) has a significant positive direct effect and positive spillover effect on the distribution of tourism resources, indicating that the improvement of TPBtE is the key to promoting global tourism, especially the rapid transportation system. It is supported that the traffic conditions are indispensable important conditions to promote the healthy development of regional tourism.

Compared with previous studies, in the analysis of spatial characteristics of highway network, the search radius mode changes from the traditional space syntax discrete space to the continuous space, and realizes the change

ISSN: 0010-8189

(C) CONVERTER 2021

www.converter-magazine.info 
from the original value of 0 or 1 to 0 to 1 , which significantly improves the calculation accuracy and provides a new possibility for the measurement of regional road network spatial structure. From the perspective of research, this paper analyze the impact of accessibility single road network variables on the spatial distribution of tourism resources from the perspectives of Closeness, Betwenness, Severance and Efficiency. In terms of research methods, the shift from traditional econometric methods to spatial models incorporating spatial effects is conducive to detecting spatial spillover effects. At present, this paper still stay at the level of static research. On the one hand, future research can collect the time series data of the road network and tourism resources in the scenic area of Sichuan-Tibet Scenic Byway, and combine the spatial panel Durbin model to further explore the characteristics of spatio-temporal evolution. On the other hand, future research can consider the influence of multiple control variables such as road network shape variables, economic foundation, and industrial structure on regional tourism development, and introduce the geographical detector method to determine the driving factors of spatio-temporal evolution, to research the influence of single dimension of road network variables on the spatial distribution of tourism resources.

\section{Acknowledgments}

This study is supported by the Chongqing Social Sciences Planning Project 2020QNJJ14.

\section{References}

[1] X. Yang, Q. Yu, Z.H. Yang, "Study on coupling evaluation and system optimization of scenic byway network," Joumal of Highway and Transportation Research and Development, vol. 37, no. 11, pp. 150-158, 2020.

[2] A. Pellegrini, S. Scagnolari, "The relationship between length of stay and land transportation mode in the tourism sector: A discrete continuous framework applied to Swiss data," Tourism Economics, vol. $27,2021$.

[3] T. Huang, J.C. Xi, Q.S. Ge, "Spatial differentiation and integration optimization of an urban agglomeration tourism system under the influence of high-speed railway network evolution," Applied Spatial Analysis and Policy, vol. 12, no. 2, pp. 349-376, 2019.

[4] Y.M. Li, C.L. Xiu, X. Kong, "Influence of land transportation network evolution on spatial structure and development of regional tourism in Zhejiang province," Scientia Geographica Sinica, vol. 38, no. 12, pp. 2066-2073, 2018.

[5] Ye,M., Wang,Z,F.,Tan,Y., The characteristics and effects of the coupling coordination between traffic and tourism development in Xiangxi region. Economic Geography, vol. 40, no. 8, pp. 138-144, 2020.

[6] Wang,F.,2020. Study on the Correlation Mechanism and Effect of Traffic Network and Tourism Spatial Structure Evolution in Southwest Frontier Mountainous Area -- A Case Study of Yunnan Province. Journal of Yunnan Minzu University (Philosophy and Social Sciences Edition),37(05):2+161.

[7] Zhang,H,Y.,2020.Agglomeration Mechanism and Response Path of Tourism Industry in Wuling Mountain Area Based on Transportation Development. Journal of Jishou University(Social Sciences),41(03):96-103.

[8] Zhao,X., Zhao,F,W.,Sun,H.,2019. A coevolution model of population distribution and road networks. Physica A: Statistical Mechanics and its Applications, 2019, 536

[9] Cooper,C,H,V., Harvey,I., Orford,S., et al.,2019. Using multiple hybrid spatial design network analysis to predict longitudinal effect of a major city centre redevelopment on pedestrian flows. Transportation:1-30.

[10] Huang,M,Z., Gu,H,Yu., Chen,Z,M.,2018. The Influence of Road Network Form on the Spatial Distribution of Urban Park System: the Case of Nansha District,Guangzhou. Journal of South China Normal University(Natural Science Edition),50(03):78-84.

[11] Xu,Z,T., Liang,J,Z.,Xu,W,X.,2021.Research on Correlation between Fuzhou Road Network Form and Retail Commercial Space Layout Based on Spatial Syntax. Journal of Geomatics:1-7. 
[12] Krugman, P. ,1991.Increasing Returns and Economic Geography. Journal of Political Economy 99.3:483-499.

[13] Proost,S.,Thisse,J,F.,2019. What can be learned from spatial economics?. Journal of Economic Literature,57(3) : 575-643.

[14] Guo,X,Y., Ming,Q,Z., Ding,Z,S.,2021.Is there spatial spillover effect of highway traffic on urban tourism economy? -- A case study of the Yangtze River Economic Belt. Journal of Sichuan Normal University (Social Science Edition), 48(02):80-91.

[15] Guo,X,Y., Mu,X,Q.,Ding,Z,S.,et.al.,2021.Spatial Spillover Effect and Its Influence Mechanism of Traffic Service Function on Tourism Efficiency:A Case Study of Yunnan Province. Geography and Geo-Information Science,37(01):126-134.

[16] Wang,Z,Y.,2020.The influence of high-speed rail traffic on the spatial spillover effect of tourism flow in China. Jinan University.

[17] Liu,J,J.,Chen,Y,B.,Qian,Q,L,.et.al.,2016.Guangzhou Comprehensive Accessibility and Its Spatial Characteristics. ECONOMIC GEOGRAPHY,36(02):45-52+73.

[18] Cooper,C,H,V.,2019.Spatial Design Network Analysis(sDNA)version 4.0 Manual.Cardiff University.

[19] Cooper,C,H,V.,Alain,J,F.,Chiaradia.,2020.sDNA:3-d spatial network analysis for GIS,CAD,Command Line\&amp;Python.Software X,12.

[20] Yang,T.,2017.Research on the morphology of multi-scale urban spatial network based on space syntax. Tsinghua University.

[21] Teng,T,W., Lin,H,L., Hu,L,L.,2020. Development of the Yangtze River Delta: Progress, Spatial Differentiation and Spatial Correlation. Journal of the University of Cambridge (Philosophy and Social Sciences),44(05):134-145.

[22] Meadowcroft,D., Gallardo,R., Anderson,A.,2019. Firm and regional economic outcomes associated with a new, broad measure of business innovation. Entrepreneurship \& Regional Development, 31(9-10) : 930-952.

[23] Wang,H,L., Hu,W,P.,Wu,C.,2010. The influence of spatial weight matrix on spatial autocorrelation: A case study of urban-rural income gap in Hunan Province. Journal of South China Normal University (Natural Science Edition),(01):110-115.

[24] R. Jackson, The Matthew Effect in Science International Journal of Dermatology, 27(1):16-16, 1988.

[25] Gu,H,Y.,Zhou,L.,Shen,T,Y.,2018. Study on the Highway Network of Urban Agglomeration in the Middle Reaches of the Yangtze River Based on Space Syntax Theory. AREAL RESEARCH AND DEVELOPMENT, 37(05):24-29. 